\title{
A Abep no contexto político e no desenvolvimento da demografia nas décadas de 1960 e $1970^{*}$
}

\author{
Elza Berquó ** \\ Maria Isabel Baltar da Rocha ${ }^{\star * *}$
}

\begin{abstract}
Este artigo analisa o contexto da criação da Abep, em 1976, considerando seu entorno, ou seja, do fim dos anos 1960 ao fim dos anos 1970, incluindo seu primeiro encontro nacional em 1978. Para a construção desse contexto, suas autoras tratam de alguns aspectos do debate que ocorria no país sobre a questão do crescimento demográfico, com ênfase na discussão política que se dava no Parlamento a partir da segunda metade dos anos 1960, bem como apresentam o percurso do surgimento das instituições técnicas e acadêmicas que atuavam no campo da demografia naquela ocasião. A questão subjacente ao artigo é procurar entender como uma associação criada sob o estímulo de recursos externos em um ambiente internacional com forte preocupação com o crescimento demográfico - e em pleno regime autoritário (embora no começo da abertura política) resultou em uma entidade pluralista e abrangente de demografia, nos enfoques utilizados e nas temáticas tratadas.
\end{abstract}

Palavras-chave: Abep. Demografia. Política de população. Parlamento. Fundação Ford.

Quando a Associação Brasileira de Estudos Populacionais (Abep) foi criada, na segunda metade dos anos 1970, o debate sobre as questões relacionadas ao crescimento demográfico já se havia iniciado há cerca de dez anos no Brasil. Estamos falando do debate desencadeado pela preocupação dos países capitalistas desenvolvidos com o aumento populacional dos países pobres e de suas grandes cidades, bem como do interesse daqueles países em reduzir esse crescimento. Debate provocado, portanto, a partir do ponto de vista neomalthusiano, que emergira no cenário internacional após a Segunda
Guerra Mundial e, especificamente, na América Latina durante os anos 1960.

Naquela ocasião também já atuavam no Brasil algumas das mais importantes instituições do campo da demografia. Instituições que desenvolviam suas atividades na esfera da administração pública, sobretudo de caráter técnico, e aquelas que trabalhavam no âmbito da universidade, ou mesmo externamente a essa, voltadas para a formação profissional e para a investigação científica. Vale anotar, desde logo, que essas últimas, constituídas a partir de 1966, realizavam seus projetos institucionais e de pesquisa, em grande parte,

\footnotetext{
*As autoras esclarecem que as idéias aqui apresentadas são o resultado de suas vivências profissionais e pessoais e de seus compromissos políticos e sociais com a temática. Neste sentido, muitas de suas contribuições que inspiram este artigo não estão referidas na bibliografia.

* Coordenadora da Área de População e Sociedade do Centro Brasileiro de Análise e Planejamento (Cebrap) e fundadora do Núcleo de Estudos de População (Nepo) da Universidade Estadual de Campinas (Unicamp).

${ }^{* \star *}$ Pesquisadora do Núcleo de Estudos de População (Nepo) da Universidade Estadual de Campinas (Unicamp) e professora colaboradora do Programa de Pós-Graduação em Demografia do Instituto de Filosofia e Ciências Humanas (IFCH) da mesma universidade.
} 
com apoio de recursos provenientes do exterior.

Conforme afirmávamos em outro trabalho:

Durante as décadas de 1960 e 1970, a interpretação dominante nas agências internacionais e de países desenvolvidos - que o crescimento populacional nos países em desenvolvimento se fazia a taxas relativamente altas e estáveis cujos resultados poderiam inibir o crescimento econômico levou a que oferecessem recursos para pesquisas nesses países, visando, primeiro, conhecer melhor a tendência e os determinantes de seu crescimento demográfico e, segundo, interferir nesse crescimento através de políticas populacionais. (Berquó, 1993, p. 167) ${ }^{1}$

O presente artigo busca visitar o contexto da criação da Abep, em 1976, considerando seu entorno, ou seja, do fim dos anos 1960 ao fim dos anos 1970, incluindo seu primeiro encontro nacional, em 1978. Cabe ressaltar que a entidade foi uma das beneficiárias desses recursos provenientes do exterior, inclusive em sua própria constituição. Para a construção desse contexto, retratamos alguns aspectos do debate que se travava no Brasil sobre a questão do crescimento demográfico, com ênfase na discussão política que ocorria no Parlamento a partir da segunda metade dos anos 1960, bem como apresentamos o percurso do surgimento das instituições técnicas e acadêmicas que atuavam no campo da demografia naquela ocasião.

A questão subjacente a este trabalho é procurar entender como uma associação criada sob o estímulo de recursos externos - em um ambiente internacional com forte preocupação com o crescimento demográfico - e em pleno regime autoritário (embora no começo da abertura política) resultou em uma entidade pluralista e com uma visão abrangente de demografia. Ou seja, resultou em uma entidade distinta do apelo neomalthusiano da época e em um fórum de discussões teórico-metodológicas e de importantes questões sócio-culturaleconômica-ambiental-demográficas, além de questões políticas e das políticas públicas.

\section{O contexto político}

Um dos principais espaços políticos da discussão sobre o crescimento demográfico no Brasil, em seus primórdios, foi o Congresso Nacional. A controvérsia despertada pelo assunto foi responsável pela constituição, em 1967, de uma Comissão Parlamentar de Inquérito (CPI) na Câmara dos Deputados - a primeira sobre o tema. Para caracterizar alguns momentos do debate que contextualizam a criação da Abep, decidimos começar enfocando a atuação do Parlamento naquela época. $A$ partir dessa atuação, por nós estudada anteriormente (Rocha, 1987 e 1993), pretendemos ainda evidenciar a participação de outros importantes atores políticos e sociais desse debate.

\section{As referências legais ou as interpretações dessas referências}

Essa discussão encontrava, no país, um quadro legislativo com características em geral consideradas natalistas (nominalmente natalistas, para alguns autores) ou encontrava uma legislação formulada em outra época, na qual não estava previsto um locus para o desenvolvimento de atividades de regulação dos nascimentos. A legislação em questão eram dispositivos referentes ao assunto, ou assim interpretados, que constavam da Lei das

\footnotetext{
1 "The establishment and strengthening of demography as an accepted intellectual discipline in Brazil would be distinctly worthwhile if only because of the importance in designing programs of all sorts for social and economic development. Even if there were no possibility during the next several decades of initiating an effective program of birth control, it would still be essential to incorporate demographic facts and demographic analysis into the study of housing, education, agriculture, employment, urban development and overall economic growth, and of course into planning in these fields. There would initially be a better appreciation of the significance of population for a variety of social and economic problems on the part of economists and other social scientists within the government, the universities, and planning and advisory agencies, and this improved understanding would ultimately have a powerful effect on informed opinion about population policies" (Coale, 1968, p. 1).
} 
Contravenções Penais, da legislação social, bem como do Código Penal.

A Lei das Contravenções Penais, promulgada durante o Estado Novo, em 1941, em seu artigo 20 proibia "anunciar processo, substância ou objeto destinado a provocar o aborto ou evitar a gravidez". Essa era, dentre as normas legais aqui referidas, a que apresentava um significado natalista mais explícito. Segundo Feiguin (1970), teria sido formulada sob a influência dos governos nazi-fascistas da Europa, que fomentavam, em seus países, políticas de teor natalista.

Ao lado de aspectos estruturais mais amplos que diferenciavam o quadro internacional e a sociedade brasileira naqueles dois momentos, durante os anos 1940 e os anos 1960, nos quais não cabe nos determos aqui, havia uma evidente pressão para se alterar essa lei por parte de atores políticos e sociais preocupados com a questão do aumento demográfico. Sob essa pressão, em 1979 essa norma legal acabou sendo modificada, ao se suprimir a proibição do anúncio de meios para se evitar a gravidez.

No que diz respeito à legislação social, o que estava em questão era, especificamente, o salário-família - norma estabelecida, de início, na Constituição de 1946, artigo 157/1, na forma de salário mínimo capaz de atender às necessidades do trabalhador e de sua família, e implementada por meio da Lei $n^{\circ} 4.266$, de 1963. Mediante essa lei, o trabalhador tinha direito a receber por cada filho com menos de 14 anos o valor correspondente a $5 \%$ do salário mínimo vigente (naquela ocasião, salário local). Ainda nos anos 1960 esse salário foi estendido para os aposentados e passou também a considerar os dependentes do trabalhador. A Constituição de 1988 incluiu o trabalhador avulso.

Em artigo que analisa a legislação social no Brasil e sua relação com a dinâmica populacional, Werneck Vianna não encontra uma conexão real entre tal legislação e o estímulo à natalidade. Sem esquecer que a ideologia do Estado Novo era nominalmente natalista, o autor considera que "a filosofia implícita da legislação consistiu, desde sua elaboração nos anos 30, em situar os direitos dos trabalhadores no nível do elementar" (Werneck Vianna, 1977 , p. 137). O salário-família se enquadraria nessa visão, tratando-se, simplesmente, de garantir a manutenção da família do trabalhador, e não de incentivá-lo a ter mais filhos.

O questionamento do efeito natalista desse dispositivo, entretanto, não era considerado na ação parlamentar. Houve tentativas de modificar ou mesmo substituir a referida norma legal já no início dos anos 1980 - embora sem êxito -, motivadas por razões explicitamente demográficas, a exemplo de procedimento semelhante utilizado nas políticas populacionais de outros países não desenvolvidos.

Por fim, o Código Penal, originário também do período do Estado Novo, datado de 1940, em seu artigo 129 definia como crime contra a pessoa, por provocar lesão corporal, "ofender a integridade corporal ou a saúde de outrem". Neste artigo vinha sendo situado, por alguns intérpretes, o ato médico da esterilização cirúrgica. No inciso III do seu parágrafo $1^{\circ} \mathrm{e}$ no inciso III do seu parágrafo $2^{\circ}$, respectivamente, julga lesão corporal de natureza grave se essa ofensa resultar em debilidade permanente, bem como perda ou inutilização "de membro, sentido ou função". A cirurgia da esterilização, segundo aqueles intérpretes, afetaria a função reprodutiva.

O dispositivo do Código Penal concernente à lesão corporal, acima mencionado, diferentemente daquele da Lei das Contravenções Penais, podia ser considerado ambíguo em sua formulação no que se refere a uma política populacional para o Brasil, por não conter referência explícita à prática da esterilização cirúrgica. Conforme anotam Barroso e Amado (1986, p. 1104), essa lei foi elaborada "numa época em que não era generalizado o recurso à esterilização com fins anticoncepcionais".

Em alguns dos projetos de lei sobre o assunto que analisamos, no entanto, essa norma é considerada proibitiva da esterilização cirúrgica como meio de limitar o número de filhos. Ressalta-se, porém, que a maior parte dos projetos que se referem à 
esterilização (no período sobre o qual nos detivemos ou mesmo posteriormente) não remete a esse dispositivo do Código Penal. No caso do projeto que finalmente resultou na Lei de Planejamento Familiar - aprovado parcialmente em 1996 e na íntegra em 1997 - não houve referência a esse dispositivo, mas ele foi uma das razões alegadas para o veto parcial do projeto pelo Executivo, decisão rejeitada pelo Congresso no ano seguinte (Brasil, Congresso Nacional, 1996).

No contexto do quadro legislativo ora exposto, e no período tratado neste estudo - entre 1966 e 1979, em pleno regime autoritário -, ocorreram importantes momentos da discussão política sobre a matéria no Congresso Nacional. Ali, de alguma maneira, expressavam-se questões também apresentadas no âmbito do Executivo e da sociedade civil, inclusive, direta ou indiretamente, por volta dos anos 1980 , questões apresentadas por membros da própria comunidade demográfica, como foi possível observar analisando os documentos do acervo do Congresso.

A discussão realizada no Parlamento no período abrangido por este trabalho ocorria por meio da apresentação de projetos de lei, de pronunciamentos de parlamentares, de palestras e seminários no âmbito das comissões técnicas, bem como por intermédio da referida Comissão Parlamentar de Inquérito. Enfatizaremos aqui a atuação dessa comissão, por seu significado pioneiro no debate, mas faremos também referência às discussões travadas nas comissões técnicas e aos projetos de lei formulados sobre o assunto.

Os questionamentos da CPI, as discussões nas comissões técnicas e os projetos de lei favoráveis ao controle da natalidade

A "Comissão Parlamentar de Inquérito para Estudar a Conveniência ou Não de um Plano de Limitação da Natalidade em Nosso País", constituída em 1967, apesar de não ter produzido um relatório substantivo, representou um relevante momento na história dessa discussão no Brasil. Na CPI, não somente aparecia o interesse do Parlamento sobre o tema, como também já se apresentavam na cena política, como seus depoentes, importantes atores políticos e sociais envolvidos com o problema. Reitere-se, ainda, que naquele ano os dois primeiros projetos de lei a respeito da matéria estavam sendo debatidos na Câmara.

Criada em decorrência de requerimento encabeçado pelo deputado Mário Covas, então líder do Movimento Democrático Brasileiro (MDB), essa comissão vinha discutir a questão da política de população referente à fecundidade, em um momento em que esse tema assumia uma relativa importância na agenda da sociedade. O tema despontara recentemente no país como um problema de caráter público, relacionado, em grande medida, ao começo da realização de atividades de controle de natalidade-planejamento familiar dirigidas às populações de baixa renda. Em 1967, essas atividades, ainda bastante incipientes e envolvendo, às vezes, pesquisas com meios anticoncepcionais, geravam estranheza e causavam acirrada polêmica.

Desse ambiente faziam parte comissões parlamentares de inquérito de âmbito estadual - no Maranhão e no então Estado da Guanabara -, reportagens da grande imprensa sobre o assunto e mobilizações de diferentes segmentos da categoria médica. Outros fatos se somaram a esses: a Igreja Católica se pronunciava, às vésperas da promulgação da encíclica Humanae Vitae, sobre a regulação dos nascimentos; os economistas neomalthusianos se manifestavam, em face de um incremento populacional que todos acreditavam estar aumentando; e, finalmente, criara-se e, logo em seguida, fomentara-se o desenvolvimento da Sociedade Civil Bem-Estar Familiar do Brasil (Bemfam), por meio de sua vinculação com a International Planned Parenthood Federation (IPPF). Ressalte-se, ainda, que quando esse tema surgiu no país, já era objeto de estudos teóricos, discussões políticas e programas específicos em nível internacional, tendo ganho espaço na América Latina a partir dos anos 1960.

Um dos motivos que provocou a emergência da referida comissão foi a denúncia, 
veiculada pela imprensa, a respeito da aplicação de dispositivos intra-uterinos em mulheres da Região Amazônica por membros de organizações estrangeiras. Esses e outros fatos acabaram por estimular o debate sobre vários aspectos referentes à questão demográfica mais ampla, e sobre as questões médicas da anticoncepção e do abortamento. Os objetivos da comissão e a composição dos seus depoentes traduzem o clima reinante na ocasião, clima esse canalizado para o Parlamento.

A CPI tinha por finalidade averiguar os seguintes aspectos:

1. estudar a conveniência ou não de um plano de limitação da natalidade em nosso País;

2. verificar a veracidade das denúncias de interferência alienígena na dinâmica populacional do País, através da aplicação de processos anticoncepcionais;

3. verificar a interferência de Entidades, Organizações, grupos nacionais ou estrangeiros, na motivação e execução de processos de limitação da natalidade;

4. constatar a aplicação sistemática ou intensiva do DIU (dispositivo intra-uterino) ou "Asa de Lipps", vulgarmente denominado "espiral", "serpentina" ou "cobrinha esterilizante" em diversas regiões do País;

5. estudar os fundamentos médico-científicos dos processos de limitação da natalidade e suas conseqüências;

6. conceituar o problema frente ao Código Penal Brasileiro;

7. verificar os aspectos moral, social, religioso, econômico e político do problema;

8. examinar os estudos feitos durante o Governo Castello Branco e divulgados sob o título "Dinâmica Populacional no Brasil";

9. constatar a ação da entidade Bemfam (Bem-Estar da Família) na execução de processos de limitação da natalidade;

10. verificar as conseqüências psicossomáticas e orgânicas nas pacientes submetidas aos processos anticoncepcionais e abortivos;

11. constatar as implicações sob os aspectos da soberania e da segurança nacional;

12. indagar a posição e as providências adotadas pelo Ministério da Saúde em relação ao problema. (Brasil, Câmara dos Deputados, 1970, p. 1)
Para tão vasto temário foram convocados 24 depoentes, de várias especialidades e/ou funções e com opiniões divergentes sobre a questão, os quais, em geral e grosso modo, podem ser divididos em dois grupos.

Um conjunto de convidados colocavase numa postura de denúncia ou de crítica à intervenção estrangeira na área do controle da natalidade, à atuação da Bemfam e à utilização pouco criteriosa do dispositivo intra-uterino (DIU), considerado, por alguns, um método abortivo. Nessa categoria podem ser classificados os depoentes deputados, os jornalistas, uma parcela dos médicos e um dos representantes da Igreja Católica.

Outro conjunto de depoentes, de modo diverso, salientava as dificuldades econômicas e sociais que, acreditavam, o crescimento demográfico iria acarretar para a sociedade e para a família, e defendia a importância das atividades de limitação dos nascimentos. Nesse grupo podem ser situados, além dos médicos ginecologistas pertencentes à Bemfam, os economistas com tendência neomalthusiana, ao lado do demógrafo e do sociólogo ali presentes, que partilhavam idéias semelhantes a esses últimos.

Apesar do conjunto de depoimentos realizados e da vasta documentação reunida, a CPI terminou por não concluir seus trabalhos. $O$ fato de a comissão não ter apresentado um parecer sobre o assunto reduz grandemente a sua importância política, do ponto de vista dos próprios objetivos da sua realização. Afinal, as atividades desse inquérito não resultaram na apresentação de propostas, nem mesmo na formulação de respostas às mais diversas indagações colocadas em seu temário.

Essa inconclusão não estava diretamente relacionada ao problema discutido, mas sim ao conturbado clima político que o Brasil atravessava, particularmente no ano de 1968. Recorde-se que, no final do mesmo ano, houve um enrijecimento do regime, com a promulgação do Ato Institucional $\mathrm{n}^{\circ} 5$ (Al-5), provocando profundas conseqüências na vida política do país, que se 
estenderam, de modo especial, ao Congresso Nacional.

Por fim, podemos afirmar que a Comissão Parlamentar de Inquérito da Câmara dos Deputados, mesmo não tendo chegado a termo, deixou sugerida, em sua convocação e em seu temário, a crítica à idéia de uma política de controle da natalidade, em um momento de grande pressão externa referente ao assunto e de grande restrição à democracia no país - restrição logo acentuada com a promulgação do mencionado Ato Institucional. Registrou, também, a presença do Parlamento nos primórdios dessa discussão no Brasil, indicando um processo político que apenas se iniciava, envolvendo as relações Parlamento-sociedade e Parlamento-Executivo. Evidenciou, ainda, a participação de importantes atores políticos e sociais, grande parte dos quais, de alguma maneira, permanece no debate até a atualidade.

Ao lado da realização dessa CPI, a Câmara dos Deputados organizou, ainda, um conjunto de reuniões públicas sobre o assunto no espaço das Comissões Permanentes (hoje, Comissões Técnicas), especificamente na Comissão de Saúde (hoje, Comissão de Seguridade Social e Família). Ao todo foram realizadas seis reuniões uma delas em 1970 e as outras cinco em 1972 - associadas à tramitação de projetos de lei sobre a matéria.

Essas reuniões foram organizadas com o intuito de discutir os temas controle da natalidade e planejamento familiar, além de focalizar as questões médico-sociais relacionadas ao planejamento familiar e ao aborto. As palestras realizadas trataram, consecutivamente, de problemas demográficos, assuntos médico-sociais do aborto, incluindo a questão do dispositivo intrauterino, população e desenvolvimento e, por fim, planejamento familiar. Assim como os depoentes da CPI, seus expositores apresentavam opiniões polarizadas sobre o tema, basicamente em torno do antinatalismo e da crítica a esta postura.

Polarização semelhante ocorreu no Simpósio sobre Problemas Demográficos Brasileiros, realizado pela Comissão de Saúde do Senado (hoje, Assuntos Sociais) em 1979. O evento reuniu, entre seus participantes, dirigentes e integrantes de organismos de planejamento familiarcontrole da natalidade, bem como representantes de entidades da categoria médica e da Conferência Nacional dos Bispos do Brasil (CNBB). Convidado para o simpósio, o ministro da Saúde recusouse a participar.

Durante todo o período estudado, o tema foi objeto de debate e o Congresso Nacional sofreu pressões das entidades privadas de planejamento familiar para legislar sobre a matéria. Vale adiantar que, tanto em 1970 como em 1972, tramitavam na Câmara dos Deputados dois projetos de lei com teor antinatalista, embora nenhum deles tivesse sido aprovado. Em 1979, porém, proposição semelhante apresentada no Senado acabou se tornando lei, em um ambiente governamental condizente com essa aprovação.

A questão foi objeto de diversos projetos de lei - instrumento mais imediato de alteração das normas legais no contexto do Congresso. Ao todo foram apresentados 13 projetos dedicados à matéria entre 1967 e 1979: 11 originários da Câmara, um do Senado e um projeto mais amplo, de reformulação da Lei das Contravenções Penais, oriundo do Poder Executivo.

A análise sistemática do processo político de discussão e decisão referente às proposições do Congresso Nacional foi realizada em dois trabalhos anteriores, já mencionados. Por ora, cabe salientar que a quase totalidade dos projetos de lei ora focalizados tinha preocupações explícitas com o crescimento da população. Essa pressão política resultou na aprovação do projeto de lei do Senado acima referido, 12 anos depois de terem sido apresentados os dois primeiros projetos de lei sobre o tema, em 1967. Essa aprovação alterava o dispositivo da Lei das Contravenções Penais, permitindo o anúncio de processos, substâncias ou objetos referentes a anticoncepção, mas mantinha a proibição em relação ao aborto.

A justificativa desse projeto evidenciava seus fundamentos em relação ao tema e, ao mesmo tempo, buscava apoiar- 
se em documentos do governo brasileiro formulados nos anos 1970, sobre os quais trataremos adiante:

[...] o controle da reprodução humana [é] uma das maiores preocupações dos estadistas e homens públicos contemporâneos, seja para limitá-lo em índices razoáveis, sobretudo nos países em vias de desenvolvimento, seja para prevenir a chamada gravidez de alto risco. A mudança proposta na Lei das Contravenções Penais buscaria viabilizar a política demográfica do Governo brasileiro, definida na Conferência Mundial de População de Bucareste, em 1974, incorporada ao Programa de Prevenção da Gravidez de Alto Risco do Ministério da Saúde, de 1977, e presente em declaração do Presidente Figueiredo, de 1979. Trata-se, assim, de "levar adiante os seus programas e métodos de controle da natalidade, que os interesses do país estão a exigir". (Brasil, Senado Federal, 1979, p. 4.848)

Entrevistado sobre o que motivou a apresentação do referido projeto, seu autor informou que havia uma atmosfera política para sua aceitação. Declarou que o general Golbery Couto e Silva, ministro do governo anterior, era interessado nesta questão e que o presidente que assumira no início do ano, João Figueiredo, já manifestara sua preocupação com o assunto. Tal aceitação do Executivo seria confirmada, segundo o parlamentar, pela própria sanção presidencial ao referido projeto. Em relação à aceitação do Senado, afirmou que o interesse demonstrado pelo Executivo teria provocado a aprovação do projeto naquela Casa (Rocha, 1992, p. 156).

A aprovação desse projeto representou o limite máximo que conseguiram alcançar, do ponto de vista legislativo, os segmentos sociais comprometidos com a proposta de uma política favorável ao controle da natalidade, sobretudo as entidades privadas de planejamento familiar - tendo na retaguarda uma posição oficial ambígua do governo brasileiro, relativamente cautelosa sobre a questão daquela política mas, nesse contexto, sempre permissiva em relação às ações das referidas entidades privadas.

Essas colocações nos remetem ao Executivo, cujas propostas, sem dúvida, repercutiam nas atividades do Congresso. A posição do poder público no Brasil - natalista, ou nominalmente natalista - foi se modificando, podendo detectar-se, nos anos 1970, algumas medidas de certa maneira relacionadas a uma política governamental na área.

O documento oficial brasileiro apresentado à Conferência Mundial de População de 1974, ao lado da afirmação sobre a importância do crescimento populacional para o desenvolvimento do país, registrava a necessidade de o Estado, quando solicitado, colocar à disposição das populações de baixa renda informações e meios referentes à regulação da fecundidade. $\mathrm{O}$ II Plano Nacional de Desenvolvimento, do mesmo ano, reiterava esse último aspecto, junto a uma concepção mais moderada acerca da importância do aumento demográfico, mostrando-se preocupado com o equilíbrio entre esse aumento e a taxa de expansão do emprego.

Por fim, o Programa da Prevenção da Gravidez de Alto Risco de 1977, que fazia parte do Plano Nacional de Saúde MaternoInfantil do Ministério da Saúde, programa esse que não chegou a ser implantado, propunha concretizar essa política, baseado em razões referentes à proteção à saúde das mães e das crianças. Acrescentemos a esses documentos a preocupação com o crescimento demográfico evidenciada em declaração do ex-presidente Figueiredo, já no começo da década de 1980. Nesse caso, esse aumento é visto como "explosivo", aumento que "devora" o crescimento econômico. "Agente de instabilidade, acarreta desequilíbrios sociais, econômicos, culturais e políticos, que reclamam profunda meditação" (Figueiredo, 1983, p. 13).

Com a ampliação da abertura política em 1979 e início dos anos 1980 e, sobretudo, com a redemocratização do país, em meados dessa década, a postura governamental a respeito do assunto foi mudando - embora, no começo, com ambigüidades -, bem como as entidades privadas de planejamento familiar perderam grandemente sua capacidade de influir, primeiramente no Executivo federal e depois no Congresso. É bastante significativo que os resultados 
de uma nova CPI, realizada no âmbito do Senado em 1983 e 1984, com grande influência dessas entidades, não tenham sido incorporados pelo novo governo que assumira com a mudança do regime político em 1985.

É igualmente emblemático que esses segmentos, embora presentes na discussão sobre planejamento familiar durante a Constituinte, não tenham participado da formulação e discussão do projeto de lei apresentado em 1991, projeto esse do qual resultou a já referida Lei de Planejamento Familiar - inspirada pela perspectiva de atenção integral à saúde e de direitos reprodutivos.

Encerrando essa reconstrução, que procurou retratar alguns aspectos do cenário político em que foi constituída a Abep - do fim dos anos 1960 ao fim dos anos 1970 -, é importante ressaltar que outros atores entraram nesse debate público a partir dos anos 1980, agora em um novo contexto de mudanças políticas e institucionais. Dentre esses atores, destaca-se o movimento feminista (Jardim, 2003), que passa a discutir e buscar saídas para o enfrentamento de várias questões referentes aos direitos das muIheres, enfatizando o direito à regulação da fecundidade, sem objetivos demográficos.

\section{O contexto institucional da área de demografia}

Nos anos 1960, contava-se com a herança dos trabalhos de Giorgio Mortara, os quais lidavam com os censos demográficos de 1940 e de 1950. O de 1960, por alegados motivos técnicos, só iria ser publicado muitos anos mais tarde, quase no final da década seguinte.

A publicação dos resultados definitivos do Censo Demográfico de 1970 propiciou farta matéria-prima para os estudiosos da área, ainda mais quando se leva em conta o vazio de vinte anos de dados censitários ocorrido após o levantamento de 1950.

Ainda no campo da disponibilidade de dados, em 1967 foi implantado no Instituto Brasileiro de Geografia Estatística (IBGE) o levantamento por amostragem de do- micílios (PNAD), visando criar um sistema contínuo de base domiciliar capaz de prover informações sobre o quadro socioeconômico do país. Na década de 1970, várias das PNADs incluíram suplementos contemplando temas demográficos, como fecundidade e migração.

Do ponto de vista da dinâmica populacional, os resultados do Censo de 1970 vieram mostrar que a população brasileira experimentara na década de 1960 , ou, mais precisamente, a partir da sua segunda metade, um primeiro declínio, passando de 6,2 (valor mantido constante de 1940 a 1960) para 5,6 o número médio de filhos por mulher. Esse descenso produziu uma redução da taxa de crescimento anual da população, a qual se havia elevado na década anterior em decorrência do declínio da mortalidade. Iniciava-se, por assim dizer, a chamada transição demográfica no Brasil.

A segunda metade da década de 1960 marcou, também, o início no país do processo de industrialização do campo e modernização agrícola, aumentando o êxodo rural; além disso, já deslanchava o processo de esgotamento das antigas áreas de fronteiras. De outro lado, as mudanças ocorridas na estrutura produtiva nacional pós-1960 implicaram a diversificação do parque industrial, abrindo novos empregos urbanos. A década de 1970 intensificou essas tendências, ressaltando-se que, mesmo com a fronteira amazônica, as migrações passaram a ser predominantemente dirigidas ao meio urbano, ou seja, esse período marcou a consolidação dos grandes centros urbanos, com o crescente processo de metropolização (Berquó, 2001).

\section{As instituições da demografia}

Da perspectiva institucional, dispunhase, no âmbito do IBGE, do Centro Brasileiro de Estudos Populacionais, da Escola Nacional de Estatística e da Revista Brasileira de Estatística, essa última alimentada, em grande medida, pelos estudos de Mortara.

O Centro Brasileiro de Estudos Populacionais, hoje Departamento de Estudos de 
População (Despo), dava continuidade às tarefas do Laboratório de Estatística, órgão do Conselho Nacional de Estatística, e que tinha a seu cargo, até o início da década de 1960 , a realização de pesquisas e estudos de interpretação dos levantamentos estatísticos brasileiros nos campos demográfico, econômico e social.

A Escola Nacional de Estatística, funcionando desde 1952, prosseguia, no período citado, com sua vocação de tentar consolidar a tarefa de formar analistas demógrafos, pela incorporação da disciplina de demografia formal ao currículo de graduação em estatística.

Fazia também parte desse cenário o Setor de Demografia do Instituto de Pequisa Econômica Aplicada (Ipea), criado em 1966 e inserido em um grupo multidisciplinar, com a finalidade de fazer o diagnóstico da área e colaborar na elaboração de um modelo econométrico brasileiro, que viria a constituir a base do então Plano Decenal de Desenvolvimento. Transformado posteriormente em uma das unidades de pesquisa do Instituto, ocupou-se de elaborar e promover uma série de estudos, em particular nas áreas de migrações internas e urbanização.

Alguns grupos esparsos dedicados à análise demográfica e integrados em órgãos públicos, como a Superintendência do Desenvolvimento do Nordeste (Sudene) e o Banco do Nordeste, complementam o quadro institucional de que se dispunha na época.

De cunho acadêmico universitário, contava-se com o recém-criado Centro de Estudos de Dinâmica Populacional (Cedip), estabelecido na Universidade de São Paulo (USP) em 1966, anexo ao então Departamento de Estatística Aplicada, da Faculdade de Higiene e Saúde Pública. Sua origem baseava-se na necessidade de dotar o meio brasileiro de centros universitários de investigação e ensino especialmente voltados para o estudo das questões populacionais (Berquó, 1980).

Este projeto fazia parte de um convênio estabelecido entre a referida faculdade e a Organização Pan-Americana da Saúde (Opas) para financiamento de pesquisa em demografia e preparação de recursos humanos, em nível de pós-graduação, em renomadas universidades americanas que contavam com programas de estudos em população.

Os primeiros integrantes do Cedip, com formação nas áreas de medicina, economia, estatística e ciências sociais, e com bolsas da Organização Pan-Americana da Saúde, credenciaram-se para o doutorado em demografia nas universidades de Michigan, Chicago e Princeton, nos Estados Unidos. O ritmo que vinha marcando as atividades desse grupo pioneiro sofreu mudanças com a saída da USP de alguns de seus membros fundadores, por força de ato de exceção do governo autoritário, em 1969.

Por outro lado, o não cumprimento, por parte da Faculdade de Higiene e Saúde Pública, do compromisso mínimo de absorver em seus quadros, após cinco anos, os integrantes do Cedip teve como conseqüência natural que o grupo se desmembrasse e que grande parte de seus profissionais fosse para outras faculdades da Universidade de São Paulo ou para outras universidades e centros de pesquisa do país. Uma parte da antiga equipe pôde ser reaglutinada no Programa de Estudos em Demografia e Urbanização (Prodeur), implantado na Fundação para a Pesquisa Ambiental da Faculdade de Arquitetura e Urbanismo da USP. Outra parte se manteve nos quadros da própria Faculdade de Higiene e Saúde Pública.

Neste contexto autoritário de exceção foi criado o Centro Brasileiro de Análise e Planejamento (Cebrap), em 1969, para abrigar professores e pesquisadores das ciências sociais que compulsoriamente deixaram a Universidade de São Paulo, inclusive alguns dos que foram afastados do Cedip.

O Cebrap deu continuidade à Pesquisa Nacional de Reprodução Humana iniciada no Cedip, a qual passou a contar não somente com seus integrantes originais, mas também com praticamente toda a equipe do Cebrap, além do apoio de recursos externos. Essa investigação, dado o seu escopo, trouxe consideráveis subsídios para a elucidação de questões básicas da problemática populacional, isto é, das inter- 
relações entre os diferentes processos de produção e a dinâmica populacional, mediados pelo papel das instituições.

Datam também desse período os primeiros passos para a constituição do Centro de Desenvolvimento e Planejamento Regional (Cedeplar), vinculado à Faculdade de Ciências Econômicas da Universidade Federal de Minas Gerais, que contou com um programa de apoio à vinda de professores visitantes na sub-área de demografia, iniciado em 1971.

Em 1974 o Cedeplar criou uma área de concentração em demografia econômica no Programa de Mestrado de Economia. Visando consolidar seu papel no campo do ensino e da pesquisa, criou um Programa de Pós-Graduação em Demografia, inicialmente com mestrado e posteriormente com doutorado.

Além de equipes da esfera de governos estaduais que estudam a dinâmica da população para fins de planejamento, implantação e avaliação de políticas públicas, são também desse período outros importantes centros e programas vinculados à universidade e/ou voltados à pesquisa (Berquó e Rocha, 1983). Estamos nos referindo ao Centro de Estudos de Recursos Humanos (CRH) da Universidade Federal da Bahia, ao Centro de Documentação e Pesquisa (Cedope) da Universidade do Vale do Rio dos Sinos, no Rio Grande do Sul, e à Fundação Instituto Joaquim Nabuco; ao Curso de PósGraduação em História da Universidade Federal do Paraná e ao Programa de Demografia Histórica do Departamento de História da Universidade de São Paulo; e aos grupos de estudiosos da área, desta universidade, constituídos na Fundação Instituto de Pesquisas Econômicas, na Faculdade de Saúde Pública e no Departamento de Geografia. Suas contribuições marcaram o cenário institucional no campo da demografia ou correlatos na época. Cada qual a seu modo, seguindo seus próprios mandatos e vocações, essas entidades continuam desenvolvendo seus trabalhos até os dias de hoje.

Esse quadro institucional presente no país era também caracterizado por um diálogo permanente com instituições e órgãos de ensino e pesquisa latino-americanos. Destacam-se, nesse sentido, o Centro Latino-Americano de Demografia (Celade) e o Conselho Latino-Americano de Ciências Sociais (Clacso).

Ao lado de seu papel pioneiro na formação de recursos humanos na América Latina, o Celade coordenou, nos anos 1960, - Programa de Encuestas Comparativas de Fecundidad para América Latina (Pecfal), envolvendo as capitais Caracas, Bogotá, Buenos Aires, México, Panamá, São José, Rio de Janeiro, Guatemala, Guaiaquil e Quito. Seu objetivo era obter informações sobre níveis e tendências da fecundidade, atitudes e opiniões sobre o tamanho desejado de família e seus diferenciais socioeconômicos, bem como acerca do conhecimento, atitudes e práticas no uso de anticoncepcionais. Ou seja, o programa dialogava com a famosa pesquisa $K A P$, em voga na época.

No Clacso, em princípios de 1971, foi criada a Comisión de Población y Desarrollo. Estruturada em três grupos de trabalho - fecundidade, migrações e informação demográfica -, essa comissão representou importante fórum de diálogo no campo demográfico. O referente à fecundidade teve seu escopo ampliado logo na primeira reunião, realizada no México, em 1972, para estudos sobre a reprodução da população. Ao revisitar, do ponto de vista de uma crítica teórico-metodológica, as pesquisas anteriores realizadas nesse campo, com ênfase especial na região da América Latina, esse grupo, que se reuniu anualmente até 1982, produziu volumosa e relevante contribuição para os estudos de população. Desde sua implantação, contou sempre com uma coordenação exercida por pesquisadores brasileiros e por várias vezes a Pesquisa Nacional sobre Reprodução Humana, conduzida pelo Cebrap, ocupou a agenda de suas reuniões.

\section{Fundação Ford: sintonia e contradição}

Ao lado das agências nacionais de fomento à pesquisa, várias fundações e organizações internacionais contribuíram para 
a construção e a consolidação institucional da demografia no país. Dado o foco deste artigo - a construção dos contextos político e institucional da criação da Abep -, a Fundação Ford ocupará papel de destaque dentre as demais, por ter desempenhado ação decisiva no apoio à criação dessa associação.

Documento sobre estratégias de operação da Fundação Ford na América Latina, de 1967, refere-se à

[...] necessidade de reforço mútuo, no interior dos países e entre eles, de iniciativas individuais dos próprios latino-americanos, dando-se ênfase ao apoio a ser concedido às lideranças regionais nas áreas de ensino, pesquisa e aplicação de economia e ciência política. $\mathrm{O}$ documento confina as atividades prioritárias a cinco setores ou campos funcionais, quais sejam, agricultura, educação, população, ciência e tecnologia e Ciências Sociais. (Miceli, 1993, p. 65-66)

Conforme Miceli (1993), a atuação da Fundação Ford na América Latina não seguiu a mesma conduta adotada em outros continentes, de privilegiar interlocuções com os governos nacionais. Ao contrário, na ação concreta, enfatizou o diálogo com instituições produtoras de conhecimento.

Considerações contidas em trabalho elaborado em 1968 por Ansley Coale, na qualidade de consultor da Fundação Ford de Nova lorque, reforçam este ponto de vista no que se refere ao Brasil. Para Coale,

dada a atual ausência de prestígio ou mesmo do aparente reconhecimento da Demografia, é fundamental plantar as sementes de seu desenvolvimento em instituições fortes e saudáveis - nas melhores faculdades onde já existam bons estudantes e pesquisa de alta qualidade, em instituições de pesquisa com boas equipes, adequadas facilidades, e uma produção científica relevante, e em agências governamentais ou de consultorias que possuam bons quadros e tenham comprovada influência e flexibilidade. (Coale, 1968, p. 1)

Dentro dessa perspectiva, ela marca sua atuação no campo de população no Brasil através de bolsas de estudos, concursos de pesquisa e programas de professores visitantes. Com a dupla finalidade de oferecer oportunidade e condições de trabalho de investigação a seus bolsistas - que vinha apoiando desde a segunda metade dos anos 1960 - quando do regresso ao país e atrair para pesquisa em população professores e investigadores com treinamento em campos afins, a Fundação Ford criou, em 1972, um Programa de Bolsas de Pesquisa.

Apoiado em um Comitê Assessor composto por personalidades nacionais de destaque na área, e sob a inteira responsabilidade da Fundação, o programa concedeu em apenas seis anos um total de 65 bolsas para investigação. Como parte desse programa, a Ford investiu intensamente nesse campo, contando com um representante especialmente dedicado aos estudos populacionais.

Duas iniciativas merecem destaque dentre as inúmeras atividades por ela desenvolvidas no período em causa. Em relação ao Cedeplar, contribuiu para que fossem abertos cursos com o fim de aglutinar economistas interessados nessa especialização. Paralelamente, com suas bolsas de doutoramento, tornou possível o treinamento, em renomados centros do exterior, de um grupo de economistasdemógrafos. Sua contribuição foi também bastante decisiva para a criação do Cebrap, em 1969, mesmo enfrentando "recusas na sede, na medida em que alguns dirigentes identificaram nessa solicitação os sentidos de uma atitude hostil ao governo brasileiro" (Miceli, 1993, p. 55).

Após 1975, o investimento da Fundação Ford dar-se-ia principalmente através do concurso de bolsas de pesquisa, uma vez que os outros dois componentes de seu programa já haviam atingido o nível desejado. É quando essa fundação pensa em transferir a liderança na coordenação do programa de estudos populacionais para uma entidade brasileira de caráter associativo. Essa idéia encontra grande repercussão no meio especializado, o qual, por sua vez, já vinha sentindo e percebendo a necessidade e oportunidade da presença no país de um órgão dessa natureza. 
Com o fim de fomentar, ampliar e fortalecer o intercâmbio científico entre os demógrafos brasileiros, como também entre estes e os demais estudiosos das questões populacionais, foi criada, em 1976, a Associação Brasileira de Estudos Populacionais (Abep), como uma associação de indivíduos.

Durante os dois anos seguintes, as relações entre a Abep e a Fundação Ford, através de seu representante, demógrafo, mantiveram-se muito estreitas. Várias atividades foram programadas e desenvolvidas conjuntamente. A transferência da responsabilidade pelo concurso de bolsas de pesquisa para a Abep deu-se de forma gradativa, três anos após sua criação, ou seja, em 1979.

Nesse contexto, vale dizer que a recémcriada Abep chegou com competência e compromisso ao seu 1 을 Encontro Nacional, realizado em Campos do Jordão, São Paulo, em 1978. O testemunho do seu sucesso pode ser avaliado pelo elevado número de participantes, 141 pessoas ao todo, pela quantidade de trabalhos apresentados, que acabaram por ocupar 642 páginas dos seus Anais, e por um temário abrangente e sensível às questões populacionais prevalecentes no país, o que pode ser observado pelo conteúdo de suas sessões temáticas.

O estudo das migrações internas incluiu urbanização, alternativas de fixação produtiva, política urbana e aspectos metodológicos. O tema mortalidade e saúde incluiu aspectos formais e técnicos, diferenciais, considerações sobre os sistemas de saúde, o papel do Estado e a democratização da saúde. Nos campos da fecundidade, nupcialidade e participação da mulher no mercado de trabalho foram tratados aspectos formais para o estudo da fecundidade e da nupcialidade, a individualização da força de trabalho e o trabalho feminino sob o capitalismo dependente.

Um conjunto de sessões sobre o Nordeste abrangeu dimensão e componentes de seu crescimento demográfico, crescimento econômico, subemprego e sub-remuneração, as distribuições de renda real e monetária e a questão agrária e o papel do Estado.

Antes de finalizar, é importante salientarmos que o apoio à criação da Abep fazia parte de um plano programático mais amplo, no qual a Fundação Ford tentava reduzir os efeitos negativos das fortes desigualdades interinstitucionais resultantes, em parte, de sua própria orientação em relação à América Latina, inclusive o Brasil, de privilegiar o apoio a centros de excelência (Miceli, 1993).

Em coerência com esta visão, a Fundação Ford apoiou também a constituição da Associação Nacional dos Centros de Pós-Graduação em Economia (Anpec), em 1973, da Associação Nacional de Pós-Graduação e Pesquisa em Educação (Anped), em 1976, e da Associação Nacional de PósGraduação e Pesquisa em Ciências Sociais (Anpocs), ainda em 1976. Ao lado das comunidades científicas criadas em âmbito nacional, a constituição do Conselho LatinoAmericano de Ciências Sociais (Clacso) contou também com o apoio da Fundação Ford.

O fato de a Abep ter sido criada como parte de um processo caracterizado por instituições que se consolidavam, produção intelectual consistente, comunidades acadêmica e técnica atuantes, bem como por interlocuções latino-americanas fortalecidas, fez dela um ator político capaz de enfrentar as contradições do apoio de organismos e fundações internacionais, as pressões referentes à questão do crescimento demográfico e os desafios do período autoritário.

Consideramos que é esse complexo processo do contexto institucional da sua criação - no cenário de uma sociedade civil que se organizava no país - que vai fornecer os principais elementos para se esclarecer a questão subjacente a este trabalho. A nosso ver, tudo isso tornou possível o surgimento e o posterior desenvolvimento de uma entidade pluralista e abrangente nos enfoques utilizados e nas temáticas tratadas. 


\section{Referências bibliográficas}

BARROSO, C. e AMADO, T. Cidadania e saúde da mulher. In: ENCONTRO NACIONAL DE ESTUDOS POPULACIONAIS, 5, Águas de São Pedro, SP, 1986. Anais... São Paulo: Abep, 1986, p. 1087-1108.

BERQUÓ, E. Apresentação. In: SANTOS, J.L.F., LEVY, M.S.F. e SZMRECSÁNYI, T. (Orgs.). Dinâmica da população: teoria, métodos e técnicas de análise. São Paulo: T.A. Queiroz, 1980, p. 1-5.

A Fundação Ford e os estudos populacionais no Brasil. Análise-balançotestemunho. In: MICELI, S. (Org.). A Fundação Ford no Brasil. São Paulo: Fapesp/Editora Sumaré, 1993, p. 167-177.

. Evolução demográfica no Brasil: um século de transformações. In: SACHS, I. e PINHEIRO, P.S. (Orgs.). Brasil: um século de transformações. São Paulo: Companhia das Letras, 2001, p. 14-37.

BERQUÓ, E. e ROCHA, M.I.B. (Orgs.). Avaliação e perspectiva. Demografia. Brasília: CNPq, 1983.

BRASIL. Câmara dos Deputados. Comissão Parlamentar de Inquérito para estudar a conveniência ou não de um plano de limitação da natalidade em nosso país (relatório dos trabalhos realizados). Diário do Congresso Nacional. Brasília, 23 set. 1970, Seção 1, p. 234. Suplemento ao n. 117.

BRASIL. Congresso Nacional. Veto presidencial (parcial). Brasília: Centro Gráfico do Senado, 1996.
BRASIL. Senado Federal. Projeto de $n^{\circ} 287 /$ 79. Diário do Congresso Nacional, Brasília, 29 set. 1979, Seção 2, p. 4.848.

COALE, A.J. Suggestions for a program to strengthen demography in Brazil. Report. Nova York, 1968. (mimeo - Documento dos arquivos da Fundação Ford).

FEIGUIN, D. Normas jurídicas e fertilidade no Brasil. São Paulo: Cedip, 1970. (mimeo)

FIGUEIREDO, J. Mensagem ao Congresso Nacional. Brasília: s.n., 1983.

JARDIM, C.R. Uma história do feminismo no Brasil. São Paulo: Editora Fundação Perseu Abramo, 2003.

MICELI, S. A aposta numa comunidade científica emergente. A Fundação Ford e os cientistas sociais no Brasil. In: MICELI, S. (Org.). A Fundação Ford no Brasil. São Paulo: Fapesp/Editora Sumaré, 1993, p. 35-97.

ROCHA, M.I.B. O Parlamento e a questão demográfica: um estudo do debate sobre controle da natalidade e planejamento familiar no Congresso Nacional. Campinas: Nepo-Unicamp, 1987, p. 165-286 (Textos Nepo, 13).

Política demográfica e Parlamento: debates e decisões sobre o controle da natalidade. Campinas: Nepo/Unicamp, 1993. (Textos Nepo, 25).

WERNECK VIANNA, L. Leis sociais e Demografia. Estudos Cebrap, São Paulo, n. 21, jul./set., p. 93-147, 1977.

\section{Abstract}

Abep in the political context and in the development of Demography in the 1960s and 1970s

This article analyzes the context of the founding of ABEP in 1976 and the historical period during which this occurred, specifically, from the mid-1960s to the late 1970s, including the organization's first national convention, held in 1978. To construct this context, the authors discuss several aspects of the debate that was going on in Brazil regarding the question of demographic growth, with emphasis on the political discussion occurring in the Brazilian Congress as of the second half of the 1960s. The authors also present a history of the emergence of technical and academic institutions that dealt with the field of Demography in Brazil at that 
time. The underlying objective of the article is to seek a clearer understanding of how an association based on stimulus and resources from abroad - in an international environment with great concern over demographic growth - and operating under an authoritarian military regime (although this latter was beginning to open up during the period studied) resulted in a broad and pluralistic organization of Demography in terms of the approaches used and the themes treated.

Key words: Abep. Demography. Population policy. Parliament. Ford Foundation.

Recebido para publicação em 01/10/2005.

Aceito para publicação em 07/11/2005. 